\section{Not just another primary care workforce crisis ... [letter]}

I write in support of David Berger's articulate challenge to the policies of the Committee of General Practice Education Directors (COGPED) ${ }^{1}$ over its relicensing of GPs returning from abroad after working within comparable health systems. As the former chairman of the Joint Committee on Postgraduate Training for General Practice (JCPTGP) who presided over the original introduction of summative assessment, a member for 14 years of the General Medical Council (GMC) and a former UK Council member of the College I offer an opinion founded upon experience of such matters.

One of the abiding principles of professional regulation, if it is not to be overbearing and attract profligate opportunity costs for both the regulator and the regulated, is the concept of a risk-based approach to the validation of the necessary skills and knowledge required for general medical practice. This is, or should be, something that is applied to the process of revalidation that the GMC plans to introduce over the next 12 months.

Berger has made several prescient representations to the GP community over recent months that should be heeded lest we experience the unintended consequences for the English workforce he sensibly predicts.

Brian D Keighley,

FRCGP, The Clinic, Buchanan Street,

Balfron, Stirlingshire, G63 OTS.

E-mail: Bkeighleylaool.com

\section{Competing interests}

David Berger and I are both non-executive directors of BMJ Publications Group Ltd.

\section{REFERENCE}

1. Berger D. Not just another primary care workforce crisis ... [letter]. Br J Gen Pract 2012; 62(598): 236.

\section{DOI: 10.3399/bjgp12X652256}

Dr Berger produced an excellent letter in May's Journal asking pertinent questions regarding experienced UK trained GPs who have worked abroad in a 'first world' setting for a few years. ${ }^{1}$ Consequently having to remain unpaid in limbo and having to jump through hurdles of unproven value to be allowed the privilege of working in the NHS again. This was a succint argument with questions to COGPED and it was very noticeable that Purvis and Irish replied to a second more generalised letter on first name terms and ignored his salient points. ${ }^{2}$

Having worked for a short time in Canada I am well aware of the high standards of GPs there, many of whom have a much wider range of clinical skills than we offer in the UK. The system of revalidation is certainly as useful as here without the layers of computerised bureaucracy.

Cynically one could ask if it is a deliberate policy to discourage doctors working abroad for longer than a year or two.

In the light of the more pragmatic approach in Wales and Scotland would it not be possible to develop a clear national consensus before we lose a cohort of talent to the old Commonwealth?

\section{Stephen Hughes,}

The Deepings Practice, Godseys Lane, Market Deeping, PE6 8DD.

E-mail: sphughesladoctors.org.uk

\section{REFERENCES}

1. Berger D. Not just another primary care workforce crisis ... [letter]. Br J Gen Pract 2012; 62(598): 236.

2. Purvis M, Irish B. Authors' response [letter]. Br J Gen Pract 2012; 62(598): 237.

DOI: 10.3399/bjgp12X652265

\section{Privatisation: an exercise in ambiguity and ideology}

I am astonished to read the assertion in the second paragraph of this article that the primary purpose of the NHS is to provide citizens with income protection in times of illness.' Our primary purpose is to provide people with health care.

Moreover, Maynard's assertion is unsustainable, since the majority of people who access the NHS have no income that requires 'protection', being children or in receipt of either pensions or benefits.

Andrew Williams,

E-mail: andrewwilliamslawaitrose.com

\section{REFERENCE}

1. Maynard A. Privatisation: an exercise in ambiguity and ideology. Br J Gen Pract 2012; 62(597): 174-175.

DOI: 10.3399/bjgp12X652274

\section{Author's response}

The provision of a universal system of health care free at the point of consumption is made possible because the NHS provides income protection for patients. Regardless of their ability to pay we treat patients ideally on the basis of need, defined as the comparative cost effectiveness of treatments competing for funding. In countries where income protection does not exist (for example, The US and China) access to health care is based on the size of your wallet. If you adhere to a universalist ideology, which I do, income protection when ill is a primary objective of a healthcare system and this is epitomised by NHS and EU social insurance systems. Without this income protection, funded by taxes and payroll contributions, we would be unable to provide health care for all citizens.

\section{Alan Maynard,}

Department of Health Sciences, University of York, York, YOIO 5DD.

E-mail: alan.maynardayork.ac.uk

DOI: 10.3399/bjgp12X652283

\section{Integrated approach to prescribing education}

Solomon et al discuss how strictly enforced prescribing guidelines can limit patient choice and may be detrimental to the doctor-patient relationship and shared decision making. ${ }^{1}$ However, in their study many GPs employed a pragmatic approach, being flexible and applying guidelines in the context of individual patients. I feel that this is a skill that needs to start being developed early on in medical training.

The General Medical Council mandates that medical graduates must be able to prescribe drugs safely, effectively, and economically'? Prescribing is one of the biggest leaps in the transition of a medical student to a doctor. However, a study done last year found that a large proportion of graduates entering the foundation programme felt under-prepared for prescribing. ${ }^{3}$ Moreover, participants reported 